\title{
A Two Phases Reputation-Based Model for Selecting Trusted Partners
}

\author{
Le-Hui Chen \\ National Chengchi University \\ E-Mail: 92356506@nccu.edu.tw \\ Woo-Tsong Lin \\ National Chengchi University \\ E-Mail: lin@mis.nccu.edu.tw
}

\begin{abstract}
Partner selection is a key issue in supply chain management, owing to its role as the critical starting point in supply chains. However, trust is crucial among supply chain participants, and lack of trust is a significant barrier to establishing collaborative partnership. This study presented a method for selecting trusted collaborative partners which comprised two phases: (1) discovery phase, during which a requestor (i.e. namely a trustor) discovered the partner candidates (i.e. namely trustees) that were willing and claimed to be capable of collaborating, and (2) selection phase, during which the trustor selected the most reputable trustees using referral and reputation systems. This study adopts referral networks to identify the objective and subjective testimonies of partner candidates from third parties (i.e. namely raters) who had previously collaborated with the trustees, and this information was then aggregated to yield a trust score. The trustee with highest score was selected as a collaborative partner. We hope the proposed model can effectively help enterprises select collaborative partners with good competence, goodwill and predictability.
\end{abstract}

Keywords: Collaboration, Collaborative Supply Chain, Trusted Partner Selection, Reputation System

\section{INTRODUCTION}

Failure to take adequate care in collaborative partner selection is a key cause of collaboration failure (Daugherty et al., 2006). Regarding partner selection in 
Collaborative Planning, Forecasting, and Replenishment (CPFR), Ireland and Crum (2005) provided the reminder: "Not all trading partners are collaborative, and you must pick your collaborative trading partners wisely and ensure that you minimize the risk of failure". In traditional supplier-buyer transaction-based relationships, enterprises base trust of their transaction partners mainly on characteristics such as capabilities and competence. If enterprises have previously never contacted or have little knowledge of the other party, they must select the partner based on limited information regarding self-claimed competence that was based on the testimony given by the parties themselves. Trust is a critical factor in commitment among supply chain partners, and lack of trust is a significant barrier to establishing collaborative partnerships; however, real gains can only be achieved when supply chain collaborative partners have mutual trust and work to make mutually beneficial business decisions and plans (Daugherty, et al., 2006). While numerous studies have examined trust in business to customer (B2C) relationships, trust in B2B relationships remains relatively neglected (Saunders, $\mathrm{Wu}, \mathrm{Li}, \&$ Weisfeld, 2004).

Partner reputation in business transactions significantly and positively impacts trust; accordingly, reputation is a critical trust-building agent where a firm is assessing potential partners with whom it has no previous experience (Kwon, \& Suh, 2004; Koufaris, \& Hampton-Sosa, 2004). Personal experience typically is more important in building trust than second hand referrals of reputation, but in the absence of personal experience, trust is frequently based on the recommendations of others (Josang, Ismail, \& Boyd, 2007). Reputation can be considered a collective measure of trustworthiness based on referrals or ratings from community members. Trust and reputation thus have become important research topics in numerous fields (Mui, Mohtashemi, \& Halberstadt, 2002).

This study developed a two phase model for selecting trusted collaborative partners. First, during the discovery phase, the trustor issues a request seeking trustees who are willing and claim to be capable potential collaborators. Second, during the selection phase, the trustor selects a highly reputable trustee with good competence, goodwill, and consistent behavior from among numerous candidates. Restated, the trustor gathers the information elements (i.e. namely testimonies such as competence, goodwill and predictability) from raters who had contacted with trustees using referral networks and reputation systems. The testimonies are then aggregated and the trust level regarding trustees is derived. Finally, the trustor selects the trustee with highest trust level to be a collaborative partner.

This study adopts objective and subjective testimonies (e.g. such as, competence, 
predictability, and goodwill) to assess the trustees to eliminate unfair subjectivity and make the reputation system more robust than traditional methods that are based solely on subjective data. The proposed model also can be implemented by software agents that can automate partner selection and reduce the search component of transportation costs; meanwhile, this study hopes the proposed model can accelerate the implementation of collaborative supply chain.

\section{RELATED WORKS}

\section{Partner Selection in Supply Chain}

Partner selection is crucial in supply chains, just as it is important as selecting a suitable partner for marriage (Ireland, \& Crum, 2005). There is extensive literature on partner selection in the supply chain or VE/VO fields. Summarizing these literatures, the research issues related to suitable partner selection can be divided into two categories: selection methods and selection criteria. The partner selection methods include qualitative, quantitative, optimization methods and Multi-Agents Systems (MAS), including the fuzzy preference programming method, integer programming, the voting analytic hierarchy process (VAHP), colony optimization, agent-based Contract Net Protocol (CNP) etc. (Mikhailov, 2002; Wu, \& Su, 2005; Liu, \& Hai, 2005; Fischer, Jahn, \& Teich, 2004; Jiao, You, \& Kumar, 2006). Meanwhile, the selection criteria used in partner selection can refer to the 23 criteria of Dickson, including net price, delivery, quality etc. (Dickson, 1996).

However, in traditional buyer-seller relationships, the above selection methods deal with criteria information that based on the supplier perspective and primarily focus on the capabilities and core competence of supplier candidates. Research issues related to inter-organizational trust are important to collaboration, but are overlooked in traditional studies of supply chains.

\section{Inter-Organizational Trust}

Trust is an important factor in collaborative supply chain and virtual organization/enterprise (VO/VE); similarly, trust is a critical factor in fostering commitment among supply chain partners. Lack of trust among supply chain partners frequently leads to inefficient performance owing to increasing transaction costs associated with the verification, inspection and certification of trading partners (Kwon, \& Suh, 2004). However, trust is not a simple phenomenon and encompasses constructs as diverse as ethics, morals, emotions, values, and natural attitudes 
(Kasper-Fuehrer, \& Ashkanasy, 2001).

There are numerous definitions of trust. However, trust has been studied in diverse contexts, by researchers from various disciplines and backgrounds, and numerous definitions have been developed. Seppanen, Blomqvist, \& Sundqvist (2007) reviewed studies of inter-organization trust conducted from 1990 to 2003, and identified numerous differences in both its conceptualization and operationalization; notably, the measurement and methodology used to study trust in inter-organizational relationships also varied. Specifically, Seppanen combined different theoretical approaches, including both the transaction cost economics and socio-psychology approaches, to capture the multi-dimensional and complex nature of trust. The economic approach to trust, including competence, predictability, contracts, etc, is frequently calculative, stressing its risk-reducing nature, and enhancing predictions or expectations regarding the future behavior of other actors. In contrast, the socio-psychological approach to trust, such as goodwill, reliability, benevolence etc, focuses on agent expectations that trading partners will behave in a mutually acceptable manner, and will act fairly when presented with opportunities.

Ratnasingam (2005) proposed that three types of inter-organizational trust existed in B2B e-commerce: competence, predictability, and goodwill trust. First, competence trust determines the ability, skills, competence, and technical knowledge of trading partners to transact correctly. Second, predictability trust depends on the ability of one party make forecasts, predictions and judgments regarding their partner based on previous experience. Finally, goodwill trust involves dependence on the care, concern, honesty and benevolence of a trading partner.

\section{Initial Trust and Reputation}

Trust has traditionally been studied in terms of long-term relationships; accordingly, trust builds incrementally and accumulates over time. Relationships among participants in collaborative supply chain as virtual business relationships may be characterized by project-based manner, neither without past history of interaction, nor any plan for future cooperation. This does not mean that trust can not exist in temporary groups; on the contrary, trust in initial relationships can often be high (Kasper-Fuehrer, \& Ashkanasy, 2001). Additionally, Jarvenpaa and Leidner (1998) noted that trust is crucially important in new and temporary organizations, since it acts as a substitute for the traditional mechanisms of control and coordination.

Initial trust lies in the temporal context of trust development. Koufaris, \& Hampton-Sosa (2004) defined initial trust is willingness to rely on a third party 
following the initial interaction with that party, yet Koufaris also believed that initial trust beliefs can be formed without any prior experience or interaction between two parties. Hampton Sosa demonstrated that perceived reputation positively influenced initial trust in a firm; restated, despite the lack of previous experience with a company, new customers could form opinions regarding its reputation, and these perceptions impacted their initial trust in the company.

Kwon and Suh (2004) contended that successful supply chain performance is based on a high level of trust and a strong commitment among supply chain partners. Kwon demonstrated that partner reputation in business transactions significantly and positively impacts level of trust; similarly, partner's reputation is a critical trust building agent for individuals with no experience of interaction with a firm, but base their willingness to do business solely on partner reputation in the market.

\section{Reputation System and Referral System}

Reputation is defined as 'what is generally said or believed about the character or standing of a person or thing'. Additionally, reputation system is based on allowing parties to rate each other, and to use the aggregation information as ratings of a specific party and derive the score in the form of reputation or trust, which can assist other parties in deciding whether to do business with that party in the future (Josang, et al., 2007). Resnick, Seckhauser, Friedman, \& Kuwabara (2000) explained why reputation system is so important in fostering trust among strangers. First, when people interact with one another over time, past history informs them of their abilities and dispositions. Second, expectations of reciprocity or retaliation in future interactions create an incentive for good behavior.

Reputation system can be considered a collective measure of trustworthiness base on the referrals or ratings from members in a community. Therefore, there are two fundamental aspects to consider (Josang, \& Ismail, 2002):

1. Propagation mechanism: This enables entities to obtain the needed information to calculate reputation score.

2. Reputation engine: This calculates the value of user reputation ratings using various inputs, including feedback from other parties.

The referral system can be used to identify available resource or target partners in the distributed environment called a referral network. The basic idea of this concept is that a query, specifying the information sought by the requestor, is sent to selected acquaintances, with the response, if given, then including an answer or a referral. 
Parties answer only if they are reasonably confident that their expertise matches the query. On the other hand, a referral is given only if the referring party has sufficient confidence in the relevance of the party being referred (Yu, \& Singh, 2003).

\section{A TRUSTED PARTNER SELECTION MODEL}

\section{Overview}

The proposed model (see Figure 1) performs partner selection in two phases, including discovery and selection phases. During the discovery phase, the enterprise, as a trustor, issues specific requirements to the parties, as partner candidates, selected from either an internal database of trustors or from the Internet; furthermore, the partner candidates (as trustees) with willingness and required competence will respond by providing specific information to the trustor regarding potential collaboration.

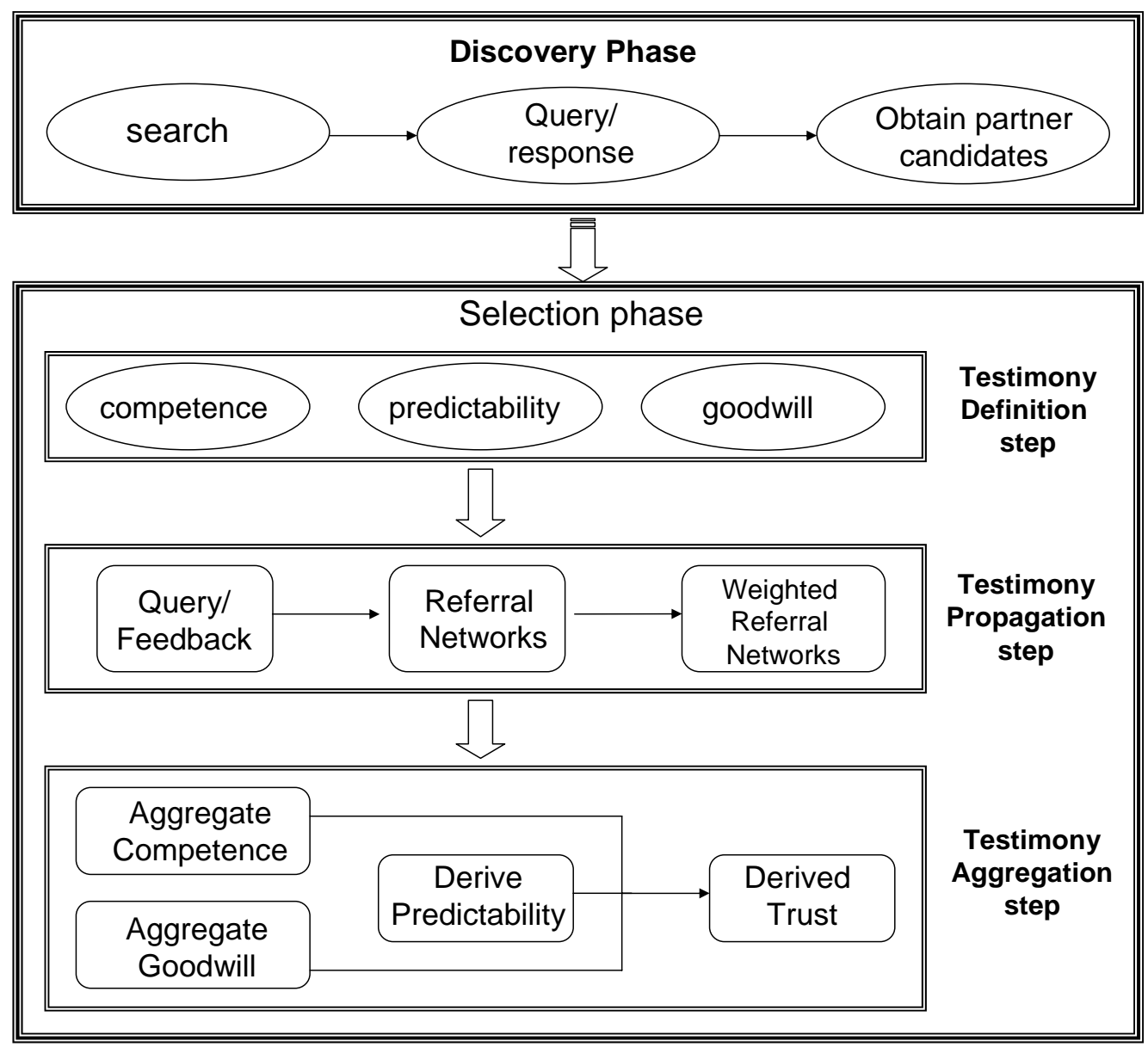

Figure 1 The trusted partner selection model 
The trustor selects a partner from among numerous trustees using a reputation and referral system during the selection phase. The selection phase includes three steps: namely, (1) testimony definition step, (2) testimony propagation step and (3) testimony aggregation step. First, during the testimony definition step, the required information elements (i.e. ratings, past history and performance etc.) are defined. The testimonies are obtained from raters with previous experience of interacting with the trustees, and contain not only the subjective perceptions from raters, but also the objective data. Second, during the testimony propagation step, the trustor requests testimonies about trustees from trusted neighbors. If the neighbor is a rater, he returns the testimonies to the trustor. Meanwhile, neighbor with no previous contact with the trustee may return the referral to the trustor and recommend others who may be able to provide the testimonies. Subsequently, the trustor can construct a referral network for all related members and calculate their weights.

Finally, during the testimony aggregation step, the trustor gathers the required testimonies from the raters, and calculates the trust scores for competence, goodwill and predictability. Subsequently, the trustor aggregates these scores into the score of derived-trust for each trustee.

\section{Discovery Phase}

The discovery phase aims to identify partner candidates who are willing and capable collaborators. Figure 2 shows that the trustor begins searching for potential partners from the internal database, Internet search engine, or associated register center where enterprises register their information (e.g. such as, name, address, web site, core competence etc.). The trustor then issues a request to enterprises (e.g. such as, enterprises A and B) after obtaining a list of enterprises.

Willing enterprises with specific required capabilities (i.e. namely partner candidates) then return messages, as follows:

$$
D \operatorname{Re}=(\text { industry _ ID, enterprise _ name })
$$

'Industry_ID' indicates the identification of a specific industry, such as construction, transportation, health etc., to which the partner candidates belong. The North American Industry Classification System (NAICS) defines codes for a variety of North American industries (NAICS, 2002). For example, agriculture was coded as ' 11 ', while manufacturing was coded as '31-33'. This study uses message elements such as 'industry_ID' and 'enterprise_name' to narrow down the search scope and reduce search costs during the selection phase. 


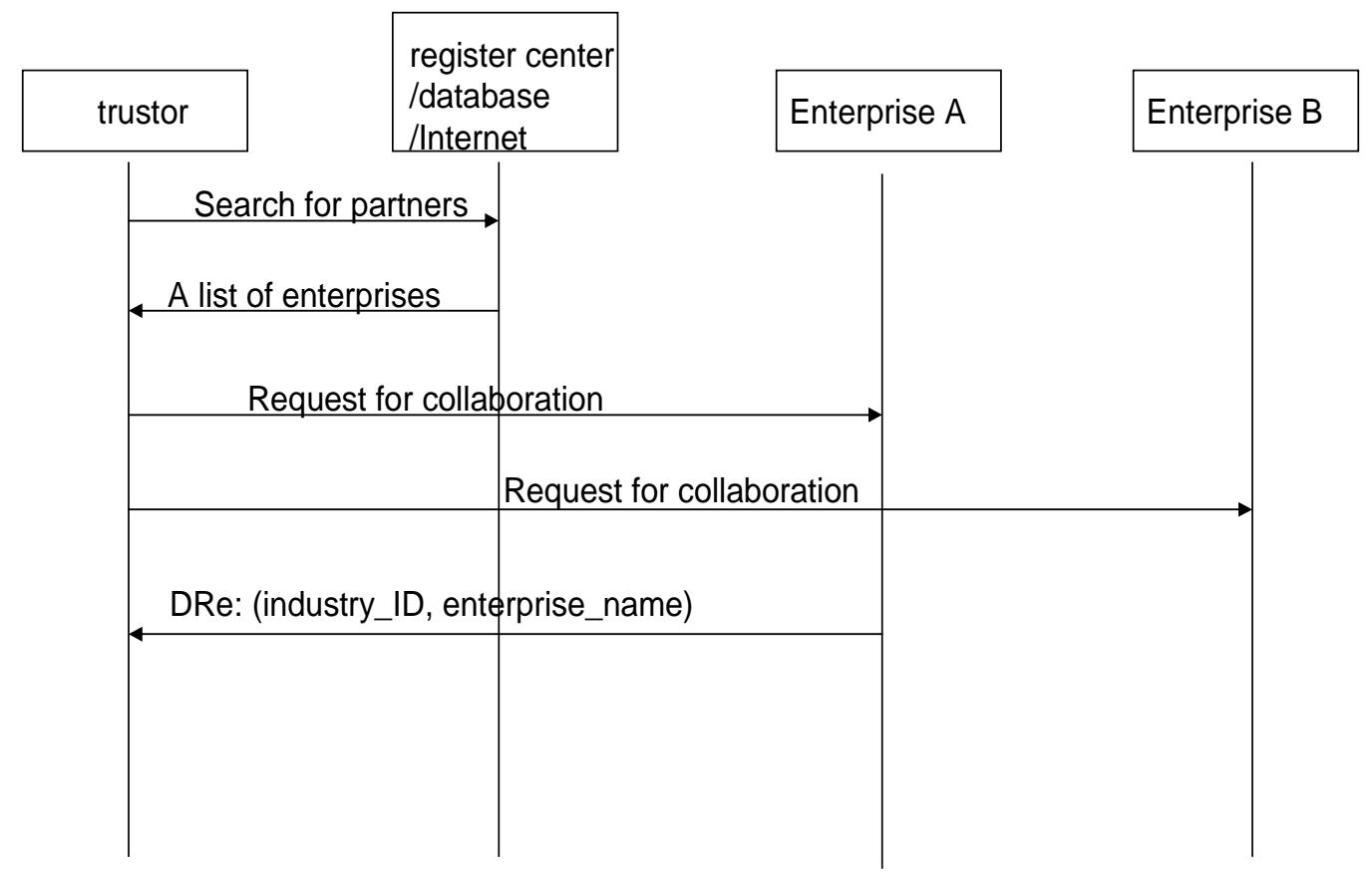

Figure 2 The processes in discovery phase

\section{Selection Phase}

\section{- Testimony Definition Step}

Testimonies used in reputation systems related to potential trusted partners in B2B environment not only consider skill, technical knowledge and abilities, but also consistent behavior, care, concern, honesty, benevolence etc. This study thus adopts the definition of trading partner trust proposed by Ratnasingam (2005). Ratnasingam identified three types of inter-organizational trust: competence, predictability, and goodwill trust, which are introduced as follows:

\section{Competence Trust}

The measurement of competence trust in this study is based on the concept of 'conformance', and was adopted by Kalepu, Krishnaswamy, \& Loke (2004) for calculating the difference between projected/agreed levels and actual performance level for measuring quality of service (QoS) in Web Services.

\section{Goodwill Trust}

The definitions of indicators of goodwill trust are adapted from Saunders et al. (2004). The indicators are identified as follows: non-opportunistic behavior (OB), affective attachment (AF), responsibility (RE), ethical behavior (EB), 
information sharing (IS), habituation (HA), and learning and information processing abilities (LIP). All indicators are rated by the raters following each instance of collaboration, and each indicator is rated as $[-1,1]$.

\section{Predictability Trust}

To measure the degree of consistency with which trustees collaborate with raters, predictability is measured based on the variation of competence and goodwill reputation. Restated, future trustee behavior can easily be predicted if his performance is less variable.

\section{- Testimony Propagation Step}

Like the social behavior of human beings, the trustor (e.g. such as, A1) searches for the rater (e.g. such as, A12) via friends or friends of friends (as recommenders, e.g. such as, A2, A3, A4 and A5). The trustor issues the request to his neighbors and obtains the associated information, in the form of testimonies or referral, from raters or recommenders. The trustor receives testimonies while the recommender is a rater; on the other hand, the trustor receives referrals while the recommender with no previous interaction history with the trustee. Based on the received messages, the trustor constructs referral networks as social relationships involving related participants (see Figure 3).

Referral networks resemble social networks containing nodes, edges, as well as relationship degree and strength. Relationship strength in referral networks describes the number of times for interaction between two adjacent nodes. Josang and Pope (2005) demonstrated how trust was weakened or diluted through transitivity. Accordingly, this study adopts the method of Yu, \& Singh (2003) to weigh the referral networks. Each node and edge in the referral networks is weighted. 


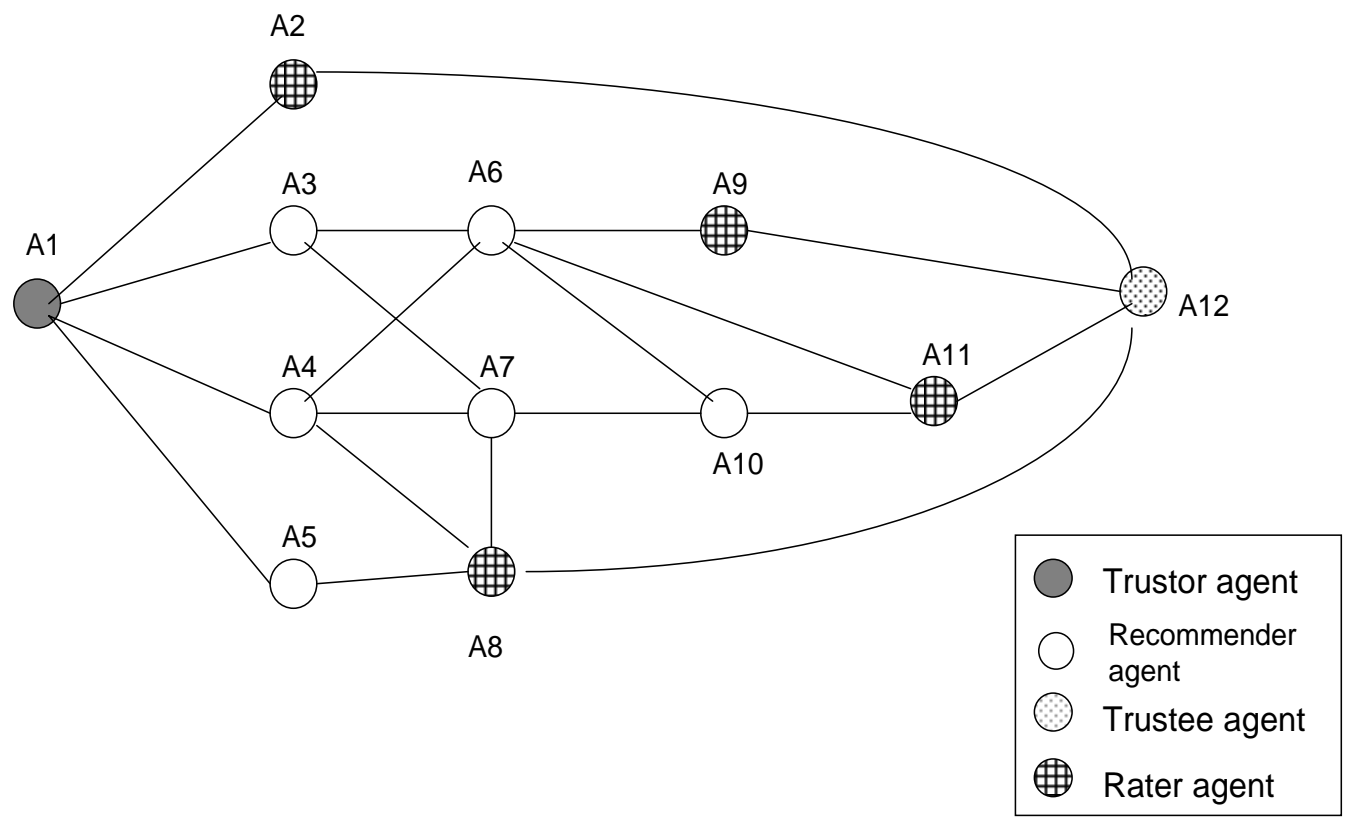

Figure 3 The referral networks

The nodes are weighted as follows:

1. The weight of the root $\mathrm{A} 1$ in referral networks (as $\mathrm{W}_{\mathrm{A} 1}$ ) is set to 1 .

2. The adjacent nodes (as A1-A2) have $\mathrm{n}$ interactions.

3. The threshold is set to $\theta$.

4. The weight of the edge between $\mathrm{A} 1$ and $\mathrm{A} 2\left(\mathrm{as} \mathrm{W}_{\mathrm{A} 1-\mathrm{A} 2}\right)$ is $\mathrm{n} / \theta$.

5. The weight of $\mathrm{A} 2\left(\right.$ as $\left.\mathrm{W}_{\mathrm{A} 2}\right)$ is the product of $\mathrm{W}_{\mathrm{A} 1}$ and $\mathrm{W}_{\mathrm{A} 1-\mathrm{A} 2}($ as $1 * \mathrm{n} / \theta)$.

The weight of nodes with multiple referrals from other recommenders is defined as follows:

1. The weight of $A m$ is $W_{A m}$.

2. The weight of $A n$ is $W_{A n}$.

3. The node Ap, an adjacent node of $\mathrm{Am}$ and $\mathrm{An}$, has weight $\mathrm{W}_{\mathrm{Ap}}$.

4. Ap and Am have $m$ interactions.

5. Ap and An have $n$ interactions.

6. $\mathrm{W}_{\mathrm{Ap}}$ is obtained as:

$$
W_{A p}=W_{A m} \times \frac{m}{\theta}+W_{A n} \times \frac{n}{\theta}
$$

The normalized weights are determined after obtaining the weights of the raters. The weights of the rater $\mathrm{i}$ (as $R_{i}$ ) for a specific trustee $\mathrm{j}$ (as $A T_{j}$ ) are expressed as 
$w r_{A T_{j}}^{R_{i}}$. Moreover, the maximum weights for all raters of trustee $A T_{j}$ are $w r_{A T_{j}}^{\max }$, and the maximum weights for all raters of all trustees are derived as $w r^{M a x}$. Finally, the normalized weights of $R_{i}$ (as $N w r_{A T_{j}}^{R_{i}}$ ) are obtained by Eqn. (1)

$$
N w r_{A T_{j}}^{R_{i}}=\frac{w r_{A T_{j}}^{R_{i}}}{w r^{M a x}}, i=1,2, \ldots r, j=1,2, \ldots k
$$

In the traditional reputation system, the problem of fake ratings occurred when the recommender did not know the trustee but returned fake testimonies. This study designs a mechanism to deal with this problem. Figure 4 illustrates the process of message transmission between trustor, rater and trustee. The trustor first sends message $\mathrm{m} 1$, containing the industry ID and the trustee name, to the rater for obtaining trustee testimony. The rater then receives the message $\mathrm{m} 1$ and sends message $\mathrm{m} 2$ to notify the trustee. The trustee then returns message $\mathrm{m} 3$, containing authorized ID, to the rater. The rater then return message $\mathrm{m} 4$, contains the subjective and objective testimonies, to the trustor. Finally, the trustor obtained the testimonies from the raters.

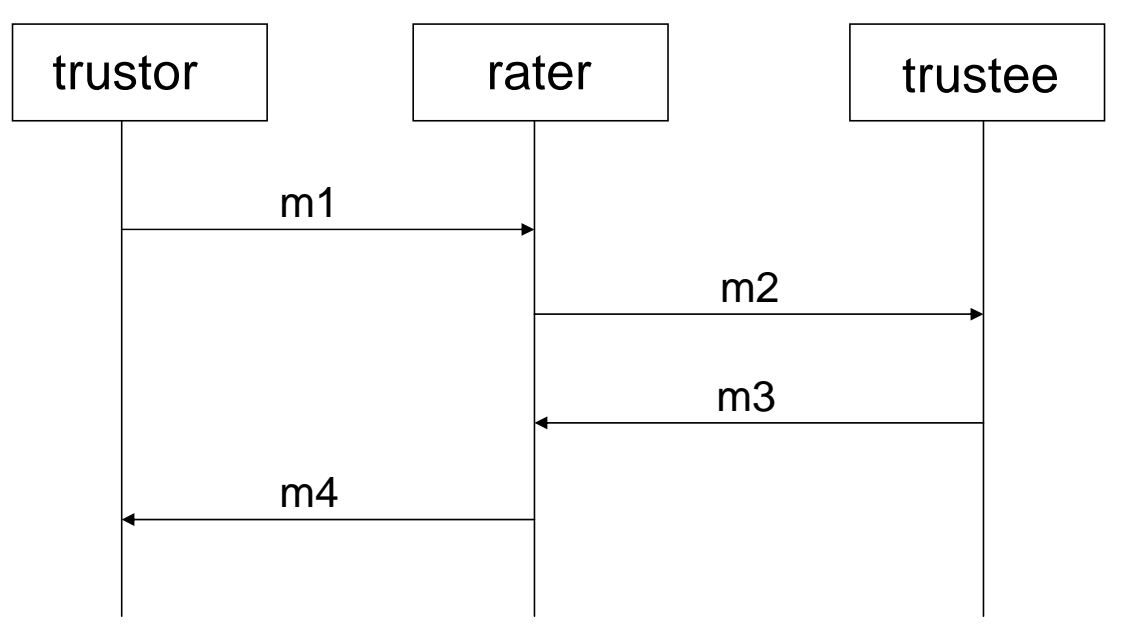

Figure 4 The message transmission in testimony propagation step

\section{- Testimony Aggregation Step}

\section{Aggregation of Competence Trust}

In this study, the competence trust is derived from the conformance of objective data. The conformance measures the difference of each indicator between the value of contract, signed by the rater and trustee before each transaction, and the value of actual performance that the trustee fulfilled the contract after each 
transaction. The conformance was then normalized and dealt with time decay factor. Subsequently, the normalized conformance was obtained to yield the competence reputation that leads to the derivation of competence trust. Competence trust is obtained as follows:

\section{(1) To Obtain the Objective Testimonies}

A set (as $\operatorname{Con}_{A T_{j}}^{R_{i}}$ ) denotes the contract signed by the rater i (as $R_{i}$ ) and the trustee $\mathrm{j}$ (as $A T_{j}$ ) before each interaction, and contains sub-sets $C_{R_{i}}^{T}$ as contract values across $n$ interactions.

$$
\operatorname{Con}_{A T_{j}}^{R_{i}}=\left\{C_{R_{i}}^{T}\right\}, \quad T=1,2,3, \ldots n
$$

The sub-set $C_{R_{i}}^{t}$ contains the values of specific indicator s (as Ind $d_{s}$, e.g. such as, quality, order fill rate, or unit cost, etc.) at the tth interaction, and the term is marked as $C_{R_{i}}^{t}\left(\operatorname{Ind}_{s}\right)$.

$$
C_{R_{i}}^{t}=\left\{C_{R_{i}}^{t}\left(\text { Ind }_{s}\right)\right\}, \quad s=1,2,3, \ldots . f
$$

A set $\operatorname{Per}_{A T_{j}}^{R_{i}}$ indicates the actual performance of trustee $A T_{j}$ in fulfilling the contract with rater $R_{i}$ following each business interaction, and contains sub-sets $P_{R_{i}}^{T}$ as the performance values across $\mathrm{n}$ interactions.

$$
\operatorname{Per} \underset{A T_{j}}{R_{i}}=\left\{P_{R_{i}}^{T}\right\}, \quad T=1,2,3, \ldots n
$$

A sub-set $P_{R_{i}}^{t}$ contains the performance value of $I n d_{s}$ at $t_{\text {th }}$ interaction, and is denoted as $P_{R_{i}}^{t}\left(\right.$ Ind $\left._{s}\right)$.

$$
P_{R_{i}}^{t}=\left\{P_{R_{i}}^{t}\left(\text { Ind }_{s}\right)\right\}, \quad s=1,2,3, \ldots f
$$

\section{(2) Conformance}

The term $D_{R_{i}}^{t}\left(I_{n} d_{s}\right)$ represents the conformance of the indicator s $\left(I n d_{s}\right)$ recorded by $\mathrm{R}_{\mathrm{i}}$ at the $\mathrm{t}_{\mathrm{th}}$ interaction. Indeed, the conformance is the difference of Ind $_{s}$ between. $C_{R_{i}}^{t}\left(\operatorname{Ind}_{s}\right)$ and $P_{R_{i}}^{t}\left(\operatorname{Ind}_{s}\right)$ calculated by the trustor. If the trustee fulfills the contract, $D_{R_{i}}^{t}\left(I_{n} d_{s}\right)$ is zero; otherwise, $D_{R_{i}}^{t}\left(I_{n} d_{s}\right)$ is the absolute value of difference between $C_{R_{i}}^{t}\left(\operatorname{Ind}_{s}\right)$ and $P_{R_{i}}^{t}\left(\operatorname{Ind}_{s}\right)$ (see equation (2)). 


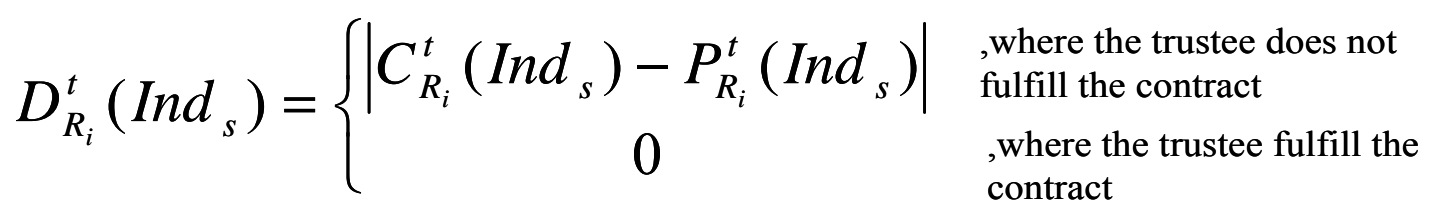

\section{(3) Normalized Conformance}

Owing to the indicators being measured using different metrics (for example, date and ratio), the conformance of specific indicators must be normalized. The trustor identifies the maximum value (as $D_{\text {Ind }_{s}}^{\max }$ ) of the conformance of Inds for all raters and across all interactions. The normalized value (as $N D_{R_{i}}^{t}\left(I n d_{s}\right)$ ) of the conformance of Inds is thus obtained via Eqn. (3).

$$
\begin{gathered}
D_{\text {Ind }}^{\max }=\max \left(D_{R_{i}}^{T}\left(\text { Ind }_{s}\right)\right), \quad i=1,2,3 \ldots . . r, T=1,2,3, \ldots n \\
N D_{R_{i}}^{T}\left(\text { Ind }_{s}\right)=\frac{D_{R_{i}}^{T}\left(\text { Ind }_{s}\right)}{D_{\text {Ind }_{s}}^{\max }}, \quad i=1,2,3 \ldots . . T=1,2,3, \ldots n
\end{gathered}
$$

\section{(4) Time Decay}

Trustee behavior may change over time. The time decay factor $\lambda$ is thus considered and older testimonies are assigned less weight than more recent feedback. The normalized conformance $N D_{R_{i}}^{t}\left(\right.$ Ind $\left._{s}\right)$ produced by a time decay factor $\lambda$ for a specific indicator $s\left(I_{n}\right)$ and a specific rater $R_{i}$ at the $t_{t h}$ interaction, and the term $T N D_{R_{i}}^{t}\left(\right.$ Ind $\left._{s}\right)$ is obtained using Eqn. (4). The term $\mathrm{t}_{\mathrm{r}}$ represents the time of the $t_{\text {th }}$ interaction, and $t_{c}$ represents current time.

$$
T N D_{R_{i}}^{t}\left(\text { Ind }_{s}\right)=\lambda^{t_{r}-t_{c}} \times N D_{R_{i}}^{t}\left(\text { Ind }_{s}\right), \quad 0<\lambda \leq 1
$$

\section{(5) Derive the Competence Reputation and Trust}

The term $\overline{\operatorname{Ind}} R_{s}$ denotes an arithmetic mean of a specific indicator s $\left(\right.$ Ind $\left._{s}\right)$ for $\mathrm{R}_{\mathrm{i}}$ across all interactions (see Eqn. (5)). 


$$
\overline{\operatorname{Ind}}_{s}^{R_{i}}=\frac{\sum_{t \in T}\left(1-\operatorname{TND}_{R_{i}}^{t}\left(\text { Ind }_{s}\right)\right)}{n}, T=1,2,3, \ldots n
$$

The competence reputation (as $Z^{R_{i}}$ ) of the trustee rated by specific rater $\mathrm{i}$ $\left(\mathrm{R}_{i}\right)$ is obtained as the sum of the weighted $\overline{\operatorname{Ind}}_{s}^{R_{i}}$ (see Eqn. (6)).

$$
Z^{R_{i}}=\sum_{s=1}^{f} \boldsymbol{W}_{s} \times \overline{\operatorname{Ind}}_{s}^{R_{i}}, \quad s=1,2, \ldots . f, \sum_{s=1}^{f} \boldsymbol{W}_{s}=1
$$

The competence trust (as $\operatorname{Comp}_{A T_{j}}$ ) for a specific trustee $A T_{j}$ interacting with rater $R_{i}$ is obtained using Eqn. (7). The term $N w r_{A T_{j}}^{R_{i}}$ was obtained using Eqn. (1) and the term $Z^{R_{i}}$ was obtained via Eqn. (6).

$$
\operatorname{Comp}_{A T_{j}}=\frac{\sum_{i=1}^{r} N w r_{A T_{j}}^{R_{i}} \times Z_{A T_{j}}^{R_{i}}}{\sum_{i=1}^{r} N w r_{A T_{j}}^{R_{i}}}, i=1,2,3 \ldots . r, j=1,2,3, \ldots k
$$

\section{Aggregation of Goodwill Trust}

One obstacle to implementing a collaborative supply chain environment is the lack of goodwill among participants in sharing sensitive information. The process to derive goodwill trust was described as: First, the subjective ratings of goodwill indicators are collected and the testimonies are then processed by filtering out unfair ratings and dealing with time decay. Subsequently, the subjective ratings are transformed into goodwill reputation scores that can be used to derive goodwill trust. Goodwill trust is obtained via the following process:

\section{(1) The Subjective Testimonies}

The set $A G_{A T_{j}}^{R_{i}}$ contains sub-sets $G_{R_{i}}^{T}$ that represent the subjective ratings supplied by rater $R_{i}$ to trustee $A T_{j}$ across $\mathrm{n}$ interactions.

$$
A G_{A T_{j}}^{R_{i}}=\left\{G_{R_{i}}^{T}\right\}, \quad T=1,2,3, \ldots n
$$

The sub-set $G_{R_{i}}^{t}$ contains the values of goodwill indicators (as $G I_{R_{i}}^{t}\left(\right.$ ind $\left._{p}\right)$ ), which are rated as $[-1,1]$ at the th interaction. The set GInd includes the goodwill indicators previously mentioned during the testimony 
definition step.

$$
G_{R}^{t}=\left\{G I_{R_{i}}^{t}\left(\text { ind }_{p}\right)\right\}, p=1,2, \cdots 7, \text { ind }_{p} \in \text { Gind }
$$

where

\section{GInd $=\{O B, A F, R E, E B, I S, H A, L I P\}$}

\section{(2) Filter Out Unfair Ratings}

Because of social relationships such as competition or collusion between raters and trustees, goodwill rating scores may be unfairly high or low. The set $H_{\text {ind }_{p}}$ contains the values of the indicator $\mathrm{p}\left(\right.$ as $\left.I n d_{p}\right)$ for all raters and across all interactions.

$$
H_{\text {ind }_{p}}=\left\{G I_{R_{i}}^{T}\left(\text { ind }_{p}\right)\right\}, \quad T=1,2,3, \ldots n, i=1,2, \ldots r
$$

The rating values about a specific indicator (e.g. such as, information sharing) for all raters and interactions are assumed to be random variables represented in the form of a statistical distribution (e.g. such as, normal distribution). That is, the $\mathrm{p}$ value of the left and right tails of the distribution can be defined, and unfair or extreme value can be screened out. Additionally, the set $F H_{\text {ind }_{p}}$ contains the value of indicator $\mathrm{p}$ (as $F G I_{w r_{i}}^{t}\left(\right.$ ind $_{p}$ ) after filtering out unfair ratings or extreme values.

$$
F H_{\text {ind }_{p}}=\left\{F G I_{R_{i}}^{T}\left(\text { ind }_{p}\right)\right\}, T=1,2,3, \ldots n, i=1,2, \ldots r
$$

\section{(3) Time Decay}

Because of previously mentioned considerations such as competence trust, this study adopts time decay factor to derive goodwill trust. The term $\lambda$ represents the time decay factor, while $F G I_{R_{i}}^{t}\left(\right.$ ind $\left._{p}\right)$ represents the indicator value after screening out the unfair rating. Finally, the term $T F G I_{R_{i}}^{t}\left(\right.$ ind $\left._{p}\right)$ is obtained using Eqn. (8).

$$
\text { TFGI }_{R_{i}}^{t}\left(\text { ind }_{p}\right)=\lambda^{t_{r}-t_{c}} \times F G I_{R_{i}}^{t}\left(\text { ind }_{p}\right), \quad 0<\lambda \leq 1
$$


The term $\bar{G}_{R_{i}}^{t}$ represents the sum of all weighted goodwill indicators for rater $R_{i}$, and is obtained using Eqn. (9).

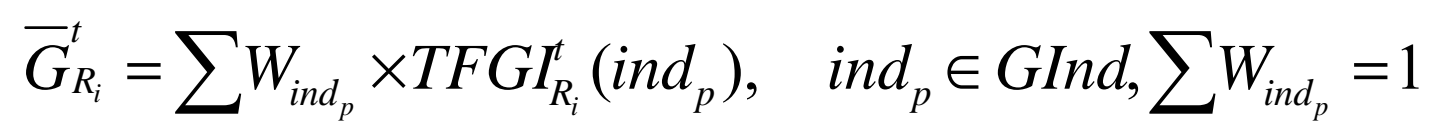

\section{(4) Changeful Goodwill Reputation}

This study uses the definition of trust proposed by Yu, \& Singh (2000), namely that reputation should be difficult to build up, but easy to destroy. The goodwill reputation rated by $\mathrm{Ri}$ at the th interaction is defined as $T_{R_{i}}^{t}$ that $-1<T_{R_{i}}^{t}<1$ and $T_{R_{i}}^{0}=0$. Goodwill reputation during the next time period is derived based on the goodwill performance during the current period. Table 1 lists the change in goodwill reputation. The term $\bar{G}_{R_{i}}^{t-1}$ is initially set to zero; additionally, the $\alpha$ represents positive evidence and the $\beta$ represents negative evidence. Thus $\alpha \geq 0$ and $\beta \leq 0$. If the trustee behaves well during the current time period, they will gain only a small score during the subsequent. On the other hand, if the trustee behaves poorly during the current time period, their reputation score will reduce markedly during the subsequent time period. This scheme may reward trustees who behave well and punish the one who betray their partner. The value of goodwill reputation $T_{R_{i}}$ is then transferred as $[0,1]$ and represented as $T T_{R_{i}}$.

\section{(5) Derive Goodwill Trust}

The arithmetic mean of goodwill reputation for $R_{i}$ across all interactions can be obtained via Eqn. (10) (as the term $\bar{T}^{R_{i}}$ ).

$$
\bar{T}^{R_{i}}=\frac{\sum_{t \in T} T T_{R_{i}}^{t}}{n}, T=1,2,3 \cdots n
$$

Finally, the goodwill trust (as $G W_{A T_{j}}$ ) for a specific trustee $A T_{j}$ is obtained by Eqn. (11). The term $N w r_{A T_{j}}^{R_{i}}$ is obtained by Eqn. (1) and the term as $\bar{T}^{R_{i}}$ is obtained by Eqn. (10). 


$$
G W_{A T_{j}}=\frac{\sum_{i=1}^{r} N w r_{A T_{j}}^{R_{i}} \times \bar{T}_{A T_{j}}^{R_{i}}}{\sum_{i=1}^{r} N w r_{A T_{j}}^{R_{i}}}, i=1,2,3 \ldots r, j=1,2,3 \ldots k
$$

Table 1 The goodwill reputation over time periods

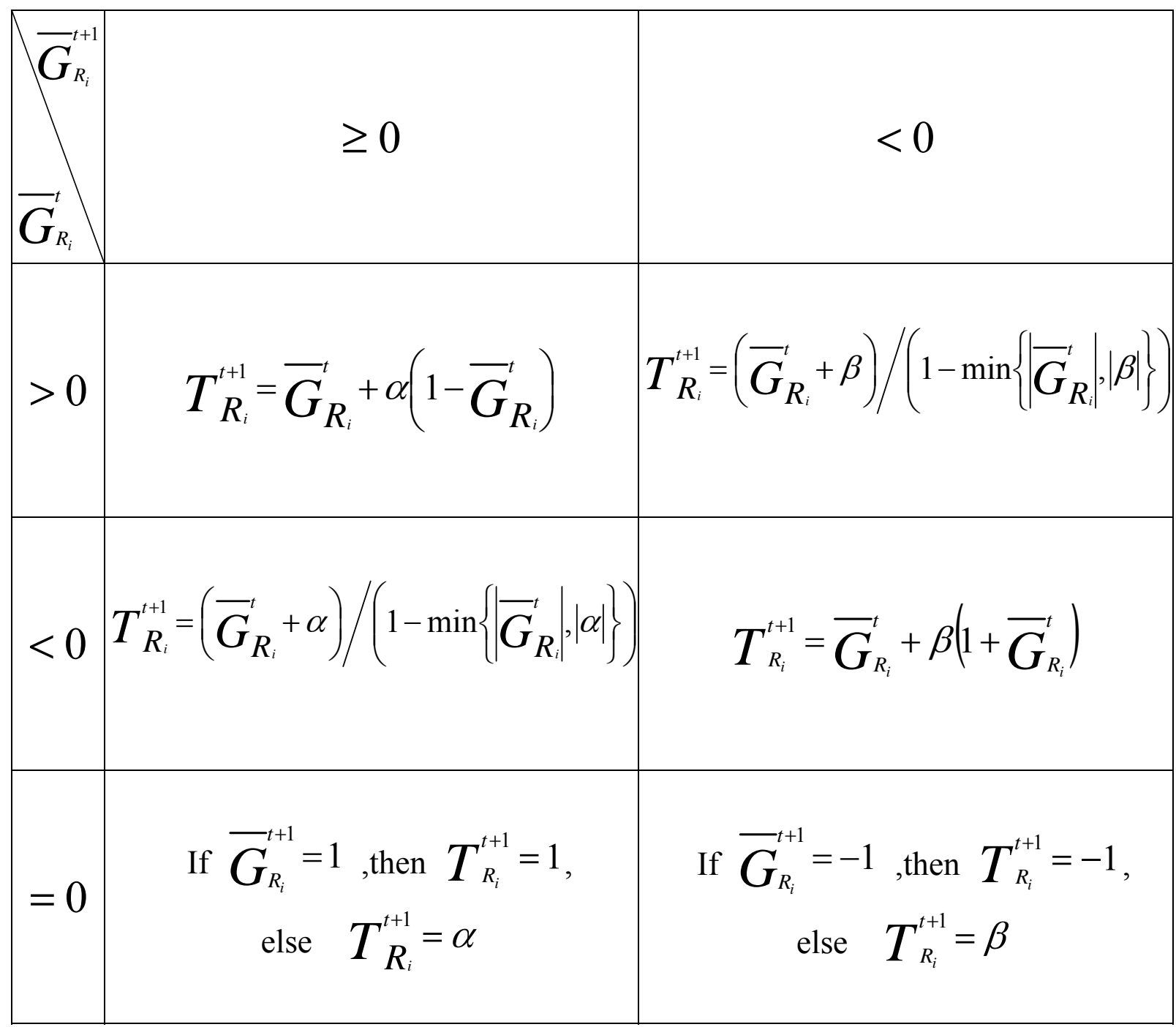




\section{To Derive the Predictability}

Predictability trust implies consistent behavior of trading partner and indicates partner reliability. This study thus defines predictability trust as being derived from the predictability of competence and goodwill. The competence predictability is derived from variance of competence reputation, and goodwill predictability is derived from variance of goodwill reputation. The ultimate aim of this method is to identify a collaborative partner with high trust level of competence and goodwill and low variance of performance.

\section{(1) To Obtain the Competence Predictability}

The term $\overline{\operatorname{Ind}}_{s}$ is an arithmetic mean of a specific indicator $\mathrm{s}$ (as $\operatorname{Ind}_{s}$ ) (see Eqn. (5)) for all raters across all interactions. Moreover, the term as $\operatorname{Var}\left(\right.$ Ind $\left._{s}\right)$ denotes the variance of competence reputation and the competence predictability as Pred_Comp ${ }_{A T_{j}}$ represented as sum of weighted terms as $\operatorname{Var}\left(\operatorname{Ind}_{s}\right)_{A T_{j}}$ (see Eqn. (12)).

$$
\begin{gathered}
\overline{\operatorname{Ind}}_{s}=\frac{\sum_{i=1}^{r} \overline{\operatorname{Ind}}_{s}^{R_{i}}}{r}, i=1,2,3 \ldots r \\
\operatorname{Var}\left(\operatorname{Ind}_{s}\right)=\frac{\sum_{i=1}^{r}\left(\overline{\operatorname{Ind}}_{s}^{R_{i}}-\overline{\operatorname{Ind}}_{s}\right)^{2}}{r-1}, r=1,2, \ldots . r \\
\operatorname{Pred} \text { Comp }_{A T_{j}}=\sum_{s=1}^{f} W_{s} \times \operatorname{Var}\left(\operatorname{Ind}_{s}\right)_{A T_{j}}, \quad \sum_{s=1}^{f} W_{s}=1
\end{gathered}
$$

\section{(2) To Obtain the Goodwill Predictability}

The term $\mu^{R_{i}}$ equals $\bar{T}^{R_{i}}$ (see Eqn. (10)), and the term $\operatorname{Var}^{R_{i}}$ indicates the variance of goodwill reputation rated by $R_{i}$. Finally, the goodwill predictability Pred_GW ${ }_{A T_{j}}$ was obtained using the sum of the weighted terms as $\operatorname{Var}_{R_{i}}$ (see Eqn. 13): 


$$
\begin{gathered}
\mu^{R_{i}}=\bar{T}^{R_{i}}, i=1,2, \ldots r \\
\operatorname{Var}^{R_{i}}=\frac{\sum_{t \in T}\left(T T_{R_{i}}^{t}-\mu^{R_{i}}\right)^{2}}{n-1}, T=1,2,3, \ldots n \\
\operatorname{Pred}{ }_{-} W_{A T_{j}}=\sum_{i=1}^{r} N w r_{A T_{j}}^{R_{i}} \times \operatorname{Var}_{A T_{j}}^{R_{i}}, \quad i=1,2, \ldots .
\end{gathered}
$$

\section{(3) Derive Predictability Trust}

The predictability of competence and goodwill (see Eqns. (12) and (13)) was aggregated to yield predictability trust for trustee $A T_{j}\left(\operatorname{as}_{\operatorname{Pr}} e d_{A T_{j}}\right.$, see Eqn. (14)).

$$
\operatorname{Pred}_{A T_{j}}=1-\left(W_{c} \times \text { Pred_Comp } A_{A T_{j}}+W_{g} \times \text { Pred_G } G W_{A T_{j}}\right), \quad W_{c}+W_{g}=1
$$

\section{Obtaining Derived-Trust}

In this study, the trust between trustor and trustee is not based on direct interaction, but rather on rater provided reputation. It was termed "derived-trust". The derived-trust (as $d t_{A T_{j}}(\alpha)$ was obtained by Eqn. (15)).

$$
d t_{A T_{j}}(\alpha)=\left(W_{c} \times \operatorname{Comp}_{A T_{j}}+W_{g} \times G W_{A T_{j}}\right) \times \operatorname{Pred} d_{A T_{j}}, \quad W_{c}+W_{g}=1
$$

\section{CONCLUSION}

When an enterprise (as a requestor) detects a new business opportunity in a changeable supply chain environment but he can not exploit it individually, the first thing he has to do is to set the goal and evaluate the risk and importance of that opportunity; subsequently, he has to find a trusted partner, whom he perhaps had never contacted with or knows little, to collaborate with. The participants to accomplish that opportunity may be come from multiple industries and various countries, so the requestor has to identify a systematic way to select his partner in a 
distributed environment.

In a collaborative environment, the enterprise has to share privacy and strategic information, like financial reports, manufacturing schedules and inventory, to his collaborative partners. The enterprise has to select a partner not only with good competence, but also with care, concern and honesty. Partner selection in traditional transaction-based B2B environments is based on candidate claims regarding their abilities, and considered competence or capability. The reputation system previously applied in $\mathrm{B} 2 \mathrm{C}$ or $\mathrm{C} 2 \mathrm{C}$ environments is based only on subjective ratings and general measures. The traditional methods for partner selection and the traditional reputation system thus are not suitable for selecting trusted business partners with fine competence, goodwill and predictability / constant behavior in B2B environments.

This study developed a model for selecting a trusted partner with fine characteristics for competence, goodwill and predictability based on subjective and objective testimonies using reputation and referral system. Additionally, this study adopts objective and subjective testimonies to evaluate the trustees to eliminate unfair subjective ratings and make the reputation system more robust than traditional methods.

This method makes the partner selection more systematic and fair than traditional methods that only adopt subjective perception and collect testimonies from partner themselves. Meanwhile, this method can be implemented as an intelligent agent system due to the complexity and complication in the process for propagation and aggregating these testimonies. During the modeling, the roles (as trustor, recommender, rater and trustee) will be defined, and the interaction between these roles can be described.

The partner selection can be automated, but then the enterprise has to negotiate the trustee who was selected about the rules for later collaboration; that is, the model in this study can not substitute the human decision in the negotiation step. However, our model can really help the enterprise selects a reputable partner during the initial step of collaboration by using a systematic and quantitative way, and it may be implemented by using intelligent agent system for reducing searching cost and accelerate the implementation of collaboration.

\section{ACKNOWLEDGEMENT}

This study was partially sponsored by National Science Council (NSC) of Taiwan. (NSC 95-2416-H-004-050-MY2) 


\section{REFERENCES}

Daugherty, P. J., Richey, R. G., Roath, A. S., Min, S., Chen, H., Arndt, A. D., et al. (2006). Is collaboration paying off for firms? Business Horizons, 49, 61-70.

Dickson, G. W. (1996). An analysis of vendor selection systems and decisions. Journal of Purchasing, 2(1), 5-17.

Fischer, M., Jahn, H., \& Teich, T. (2004). Optimizing the selection of partners in production networks. Robotics and Computer-Integrated Manufacturing, 20, 593-601.

Ireland, R. K., \& Crum, C. (2005). Supply chain collaboration: how to implement CPFR and other best collaborative practices, Florida: J.ROSS publishing.

Jarvenpaa, S. L., \& Leidner, D. E. (1998). Communication and trust in global virtual teams, Organization Science, 10, 791-815.

Jiao, J., You, X., \& Kumar, A. (2006). An agent-based framework for collaborative negotiation in the global manufacturing supply chain network. Robotics and Computer-Integrated Manufacturing, 22, 239-255.

Josang, A., \& Ismail, R. (2002). The Beta reputation system. Paper presented at the $15^{\text {th }}$ Bled Electronic Commerce Conference, Bled, Slovenia.

Josang, A., \& Pope, S. (2005). Semantic constraints for trust transitivity. Paper presented at the Asia-Pacific Conference on Conceptual Modeling (APCCM'05 ), Newcastle, Australia.

Josang, A., Ismail, R., \& Boyd, C. (2007). A survey of trust and reputation systems for online service provision. Decision Support Systems, 43, 618-644.

Kalepu, S., Krishnaswamy, S., \& Loke, S. W. (2004). Reputation=f(user ranking, compliance, verity). Paper presented at the IEEE International Conference on Web Services (ICWS 2004), San Diego, California, USA.

Kasper-Fuehrer, E. C., \& Ashkanasy, N. M. (2001). Communicating trustworthiness and building trust in interorganizational virtual organizations. Journal of Management, 27, 235-254.

Koufaris, M., \& Hampton-Sosa, W. (2004). The development of initial trust in an online company by new customers. Information \& Management, 41, 377-397.

Kwon, I.W., \& Suh, G. T. (2004). Factors affecting the level of trust and commitment in supply chain relationships. The Journal of Supply Chain Management, 40(2), 4-14.

Liu, F.H., \& Hai, H. L. (2005). The voting analytic hierarchy process method for selecting supplier. Int. J. Production Economics, 97, 308-317.

Mikhailov, L. (2002). Fuzzy analytical approach to partnership selection in formation 
of virtual enterprises. Omega, 30, 393-401.

Mui, L., Mohtashemi, M., \& Halberstadt, A. (2002). A computational model of trust and reputation. Paper presented at the $43^{\text {rd }}$ Hawaii International Conference on System Sciences (HICSS-35'02), Hawaii, USA.

NAICS (2002). 2002 NAICS Codes and Titles. Retrieved December 20, 2006, from http://www.census.gov/epcd/www/naics.html.

Ratnasingam, P. (2005). Trust in inter-organizational exchanges: a case study in business to business electronic commerce. Decision Support System, 39, 525-544.

Resnick, P., Seckhauser, R., Friedman, E., \& Kuwabara, K. (2000). Reputation systems. Communication of the ACM, 43(12), 45-48.

Saunders, C., Wu, Y., Li, Y., \& Weisfeld, S. (2004). Interorganizational trust in B2B relationships. Paper presented at the $3^{\text {rd }}$ International Conference on Entertainment Computing (ICEC'04), Netherlands.

Seppanen, R., Blomqvist, K., \& Sundqvist, S. (2007). Measuring inter-organizational trust - a critical review of the empirical research in 1990-2003. Industrial Marketing Management, 36, 249-265.

Wu, N., \& Su, P. (2005). Selection of partners in virtual enterprise paradigm. Robotics and Computer-Integrated Manufacturing, 21, 119-131.

Yu, B., \& Singh, M.P. (2000). A social mechanism of reputation management in electronic communities. LNAI, 1860, 134-165.

Yu, B., \& Singh, M.P. (2003). Searching social networks. Paper presented at the second international joint conference on Autonomous Agents and Multi-Agent Systems (AAMAS'03), Melbourne, Australia. 